(C) 2020 Cambridge University Press. Access to this work was provided by the University of Maryland, Baltimore County (UMBC) ScholarWorks@UMBC digital repository on the Maryland Shared Open Access (MD-SOAR) platform.

Please provide feedback Please support the ScholarWorks@UMBC repository by emailing scholarworks-group@umbc.edu and telling us what having access to this work means to you and why it's important to you. Thank you. 


\section{Journal of Benefit-Cost Analysis}

圈圈圈 CAMBRIDGE

\section{Efficiency without Apology: The Place of the Marginal Excess Tax Burden and Redistribution in Benefit-Cost Analysis}

\begin{tabular}{|c|c|}
\hline Journal: & Journal of Benefit-Cost Analysis \\
\hline Manuscript ID & BCA-2020-0025.R1 \\
\hline Manuscript Type: & Article \\
\hline $\begin{array}{r}\text { Date Submitted by the } \\
\text { Author: }\end{array}$ & $\mathrm{n} / \mathrm{a}$ \\
\hline Complete List of Authors: & $\begin{array}{l}\text { Boardman, Anthony; University of British Columbia, } \\
\text { Greenberg, David; University of Maryland - Baltimore County, } \\
\text { Economics; } \\
\text { Vining, Aidan; Simon Fraser University } \\
\text { Weimer, David; University of Wisconsin-Madison, La Follette School of } \\
\text { Public Affairs }\end{array}$ \\
\hline Classifications: & Theory \\
\hline Keywords: & $\begin{array}{l}\text { allocative efficiency, marginal excess tax burden, distributional weights, } \\
\text { tax system, social welfare function }\end{array}$ \\
\hline Abstract: & $\begin{array}{l}\text { Some issues in the application of benefit-cost analysis (BCA) remain } \\
\text { contentious. Although a strong conceptual case can be made for taking } \\
\text { account of the marginal excess tax burden (METB) in conducting BCAs, it } \\
\text { is usually excluded. Although a strong conceptual case can be made that } \\
\text { BCA should not include distributional values, some analysts continue to } \\
\text { advocate doing so. We discuss the cases for inclusion of the METB and } \\
\text { the exclusion of distributional weights from what we refer to as "core" } \\
\text { BCA, which we argue should be preserved as a protocol for assessing } \\
\text { allocative efficiency. These issues are topical because in this journal Bos, } \\
\text { van der Pol, and Romijn (2019) recommend ignoring the METB on the } \\
\text { grounds that desirable distributional effects offset its cost. We challenge } \\
\text { their logic and explain why it may encourage inefficient policies. We } \\
\text { conclude that distributional weights can be incorporated into a weighted } \\
\text { BCA as supplement to core BCA, but caution that national heterogeneity } \\
\text { requires context-specific weights. }\end{array}$ \\
\hline
\end{tabular}




\title{
Efficiency without Apology: Consideration of the Marginal Excess Tax Burden and Distributional Impacts in Benefit-Cost Analysis
}

By

\author{
Anthony E. Boardman, David H. Greenberg, Aidan R. Vining, and David L. Weimer
}

May 22, 2020

\author{
Anthony E. Boardman, University of British Columbia, Anthony.Boardman@sauder.ubc.ca \\ David H. Greenberg, University of Maryland, Baltimore County, dhgreenb@umbc.edu \\ Aidan R. Vining, Simon Fraser University, vining@ @fu.ca \\ David L. Weimer, University of Wisconsin-Madison, weimer@lafollette.wisc.edu
}

\begin{abstract}
Some issues in the application of benefit-cost analysis (BCA) remain contentious. Although a strong conceptual case can be made for taking account of the marginal excess tax burden (METB) in conducting BCAs, it is usually excluded. Although a strong conceptual case can be made that BCA should not include distributional values, some analysts continue to advocate doing so. We discuss the cases for inclusion of the METB and the exclusion of distributional weights from what we refer to as "core" BCA, which we argue should be preserved as a protocol for assessing allocative efficiency. These issues are topical because in this journal Bos, van der Pol, and Romijn (2019) recommend ignoring the METB on the grounds that desirable distributional effects offset its cost. We challenge their logic and explain why it may encourage inefficient policies. We conclude that distributional weights can be incorporated into a weighted $\mathrm{BCA}$ as supplement to core $\mathrm{BCA}$, but caution that national heterogeneity requires contextspecific weights.
\end{abstract}




\section{Introduction}

Over the last few decades, a broad consensus has emerged on many important conceptual issues in benefit-cost analysis (BCA). As a result of this, and the fact that BCA is a valuable practical input to decision making, BCA is now applied in a broad range of policy areas from physical infrastructure and transportation to environmental and social policies. Nonetheless, some issues remain contentious. One such issue is whether analyses should take account of the marginal excess tax burden (METB), which measures the social cost of raising an additional dollar of tax revenue. ${ }^{1}$ Despite fairly broad theoretical agreement that the METB should be taken into account in BCAs, in practice it is usually ignored. Another important issue is how to deal with the distributional impacts of policies. Conceptually, these two contentious issues can be, and usually are, treated independently. However, these two issues have become intertwined in claims that the METB should be ignored in BCA.

To explicate this intertwining, we first review the rationales for the inclusion of a measure of the METB in BCA and conclude that it should be. We also discuss estimation of the METB and present recent estimates from a number of wealthy countries. Next, we discuss how BCA might treat distributional issues. Although BCA has its foundations in welfare economics, the welfare term can be misleading: BCA assesses allocative efficiency defined as the maximization of potential Pareto improvements. That narrow definition allows it to identify policies that maximize net benefits, where benefits are measured in terms of willingness to pay for positive impacts and willingness to accept for negative impacts, and costs are measured in terms of the opportunity cost of the real resources needed to produce the impacts. As it assesses

\footnotetext{
${ }^{1}$ Thus, the total cost of raising a dollar of public funds is usually labeled as the marginal cost of public funds (MCPF). The MCPF is the dollar that is transferred from taxpayers to the government plus the METB. That is, MCPF $=1+$ METB (Dahlby 2008).
} 
net benefits taking the existing distribution of wealth as given, and it does not require that the positive net benefits of any policy actually be redistributed to convert the potential Pareto improvement into an actual Pareto improvement, it is often an incomplete assessment of welfare. Nonetheless, as allocative efficiency should almost always be one of the goals of public policy, BCA can contribute to better public policy by providing protocols for systematically assessing efficiency across policies to facilitate their comparison along with other goals. We refer to this assessment of allocative efficiency as "core" BCA.

Although core BCA defined in this way does not take account of distributional values, we argue that it does promote good public policy by facilitating a transparent assessment of tradeoffs between efficiency and equity. In contrast, social welfare functions (SWFs) that are based on proxies for individuals' utilities using distributional weighting to combine efficiency and equity into a single measure obscure this tradeoff. In some circumstances, these combined measures may convey useful information, but we argue that any distributional or equity weighting scheme should be in addition to, rather than directly incorporated into a core BCA.

Our argument that core BCAs should not directly incorporate distributional weights, yet should include a measure of the METB, is important and topical because the Office of Management and Budget (2019) is considering recommending inclusion of the METB in its guidance for the conduct of Regulatory Impact Analyses. In contrast, in a recent article published in this journal, Bos, van der Pol, and Romijn (2019), hereafter BPR, recommend ignoring the METB in practice because, they argue, desirable distributional effects offset its cost. If BPR's argument were correct, then it would (apparently) simplify the application of BCA by removing the need to assess changes in net government revenue, to identify the appropriate source or sources of marginal tax revenue, to determine the appropriate rate of METB, and to apply the 
rate to the net change in government revenue. More fundamentally, however, it would lead to the support of potential policies that, in fact, do not increase economic efficiency. After making the case for inclusion of the METB, we then consider alternative frameworks for taking distributional effects into account in policy analysis, and argue in favor of multi-goal analysis. Then, we review the BPR argument to ignore the METB and challenge its logic. The final section contains a brief conclusion.

\section{The METB in BCA: Rationale and Estimates}

\subsection{The Rationale for Including the METB in BCA}

The general equilibrium model of the idealized economy concerns the efficiency of the equilibrium: in an economy in which consumers get positive but declining marginal utility from the consumption of goods, and all the markets for goods and the inputs that produce them are complete, competitive, and undistorted, a Pareto efficient equilibrium distribution of inputs and goods results (Weintraub 1983). The equilibrium takes as given the initial distribution of endowments of resources within the economy, and therefore may not be socially optimal in the sense that a consensus of disinterested observers would prefer some alternative distribution. Nonetheless, in the absence of missing or distorted markets (market failures), any reallocation of resources will make at least some people worse off even with redistribution from winners to compensate losers. Where there are missing and distorted markets, public policies that would yield Pareto improvements would be theoretically possible. However, because reallocations to achieve actual Pareto improvements are usually impractical, applied welfare analysis typically assesses efficiency in terms of potential, rather than actual, Pareto improvements (Kaldor 1939, Hicks 1939, Scitovsky 1941). 
Using the Kaldor-Hicks-Scitovsky framework, analysts can then employ the protocols of BCA to assess the net benefits of policy changes: interpreting positive net benefits as indicating a potential Pareto improvement and thus assessing the relative allocative efficiency of alternative policies. Although it is rarely articulated explicitly, BCA does so on the basis of some version of methodological individualism (Heath 2005). Although methodological individualism has strong and weak versions, in its essence, it maintains that the basic unit of analysis is the individual rather than the clan, the class, "the volk", the monarch, the state or whatever (Hausman 2018, Norris 2020). ${ }^{2}$ BCA valuation, therefore, depends on individuals' monetary valuations of their own changes in utilities rather than on some socially determined valuation of outcomes.

In the BCA context, the choice among policies should take account of the expected behavioral responses of individuals that the policy alternatives will elicit, including those resulting from any taxes needed to fund them. Directly or indirectly, this derives from individuals' valuations, whether in terms of their willingness to pay or their willingness to accept (Kahneman, Knetsch and Thaler 1990, Plott and Zeiler 2005). For example, the benefits of some public investments in an increment of education or training primarily accrue to individuals in terms employment productivity or non-employment cognitive or related non-cognitive benefits. This orientation, of course, does not forestall reasonable aggregation of these individuals into useful categories such as (potential) "program participants" versus the "rest of society." Most

\footnotetext{
2 Joseph Schumpeter was the first to use the phrase "methodological individualism" in English, but its philosophical and economic roots lie in the liberal tradition of John Locke, Adam Smith, J.S. Mill, and many other thinkers of the European Enlightenment (Hodgson 2007). The specific application of this liberal philosophy to applied public policy, and to BCA specifically, can be traced historically to pioneering public administrators William Petty, Edwin Chadwick and, especially, Jules Dupuit (see, for example, Talvitie 2018 on these antecedents).
} 
BCA scholars would agree that it also does not exclude behavioural-grounded extensions to include adjustments for market failures and for evidence-grounded behavioural biases (Arrow 1994, Robinson and Hammitt 2011, Chetty 2015, Weimer 2017).

As we discuss later in more detail, a BCA focus on efficiency, which attempts to determine whether a policy initiative results in a potential Pareto improvement, does not mean that the policy should not seek to promote desirable social goals other than efficiency. The goals that are relevant to addressing any important policy issue are often multiple and, from a resource allocation perspective, conflicting, but they do almost always include improving allocative efficiency. Where efficiency is the only goal relevant to policy choice in a given context, BCA would be an appropriate decision rule. Although critics of BCA often frame it as a decision rule, we know of no institutional setting in which it plays this role for major policy decisions. Goals other than efficiency, such as a more equal distribution of wealth in society, are often relevant to policy choice. Thus, BCA serves as a systematic protocol for assessing relative efficiency in the context of multi-goal analysis. In this context, ideally, public officials consider tradeoffs among relevant social goals in selecting alternative policies. BCA informs rather than decides policy; we argue it is almost always useful because efficiency is almost always a relevant policy goal. ${ }^{3}$

BCA can make the greatest contribution to promoting good public policy by assessing only efficiency impacts. Comprehensively taking account of all of the efficiency impacts of policies often poses a challenge in practice. An important impact that is commonly ignored is the inefficiency resulting from raising the taxes required to fund the purchase of resources required

\footnotetext{
${ }^{3}$ Recognizing the prevalence of inefficient rent seeking in representative governments and the zealotry of bureaucrats in seeking potentially inefficiently large budgets, William Niskanen (1991), a pioneering BCA practitioner in the U.S. federal government, described himself as a "zealot for efficiency." One need not be a zealot to want political decision makers to consider efficiency in policy choices.
} 
for public programs. For example, in examining official BCA guidebooks from the United States, the United Kingdom, Australia, and New Zealand, Abelson (2020) found that only the latter country recommended routinely including METB in their analyses. The METB may be ignored because analysts think that revenue extracted from taxpayers is essentially a transfer that does not affect efficiency. However, this approach ignores the actual social cost of raising tax revenue. Raising tax revenues requires the expenditure of real resources and typically distorts markets. The social cost of these expenditures and distortions, the METB, should be taken into account in a comprehensive benefit-cost analysis. ${ }^{4}$ This involves applying an estimate of the METB to the net changes in government revenue resulting from the policy change being assessed; see, for example, Boardman et al. (2018). Of course, the METB is not relevant when government revenues are not affected by any of the project alternatives examined, or when positive and negative changes in government revenue exactly net out, or when public funds are raised via lump sum taxes (such as poll taxes or levies on monopoly rents), or when, in practice, the scale of any changes in revenue are trivial relative to the scale of other changes in allocative efficiency.

\subsection{Estimates of the METB}

As most distortions induced by income taxes occur in labor markets, most estimates of the METB — when an income tax is the marginal source of government revenue — use labor supply

\footnotetext{
${ }^{4}$ In developed economies with efficient public institutions, market distortions effectively comprise the entire METB because the incremental administrative and compliance costs of increasing revenue within the existing tax system are relatively very small. In contrast, the incremental resource costs of increasing tax revenue can be quite large in developing countries with limited administrative capacities and can therefore be a potentially substantial component of the METB.
} 
elasticities. Generally, these estimates are based on compensated labor supply elasticities, rather than uncompensated labor supply elasticities. However, Fujiwara (2010) reasonably argues that — unless the policy being subjected to BCA sufficiently benefits the taxpayers who fund it so that they are, in effect, compensated for their taxes, which seems unlikely to occur in most instances-METB estimates that rely on uncompensated labor supply elasticities should be used in BCA. Moreover, except under limited special circumstances, such as when the labor supply is completely inelastic, the marginal cost of public funds (MCPF) is only equal to METB +1 when the latter is based on uncompensated labor supply elasticities (see Dahlby 2008).

Table 1 summarizes estimates of the METB from 11 studies that are based on uncompensated labor supply elasticities. Although these uncompensated estimates show considerable variability, the mid-points of all but one range between 0.12 and 0.34 cents per dollar. The average of the mid-point estimates is 22.6 cents per dollar and the median is 19 cents per dollar. Looking at only the six estimates for the United States, the average of the mid-points is 21.4 cents per dollar and the median is 16.5 cents per dollar. Estimates based on compensated labor supply elasticities tend to be larger than those summarized in the table because the reduction in hours worked from a given tax increase tend to be larger.

TABLE 1

Estimates of the Marginal Excess Tax Burden

\begin{tabular}{lccc}
\hline Study & Country & METB & $\begin{array}{c}\text { Mid-Point of METB } \\
\text { Estimate }\end{array}$ \\
\hline Dahlby (1994) & Canada & $0.09-0.38$ & 0.235 \\
Stuart (1984) & USA & 0.43 & 0.430 \\
Fullerton and Henderson (1989) & USA & $0.06-0.17$ & 0.115 \\
Ballard et al. (1985) & USA & $0.12-0.23$ & 0.185 \\
Campbell and Bond (1997) & Australia & 0.19 & 0.190 \\
Judd (1985) & USA & 0.12 & 0.124
\end{tabular}


Tran and Wende (2017)

Ahmad and Croushore (1994)

Gruber and Saez (2002)

Kleven and Kreiner (2006)

Ruggeri (1999)
Australia

USA

USA

UK

Canada
0.34

0.121-0.167

0.285

0.26

0.18
0.340

0.144

0.285

0.260

0.180

Sources: The estimates for the first five rows are from studies using uncompensated labor supply elasticities and are from Daniel Fujiwara, 2010, Table 3.1. The next estimate is from Judd (1985). The following estimate is from Tran and Wende (2017). This study appears to have used uncompensated labor supply elasticities but is not entirely clear on this point. The estimates in the remaining four rows are from Dahlby (2008, Table 5.3). These four estimates were converted to METB estimates from the MCPF estimates reported by Dahlby by subtracting one.

Although the estimates in Table 1 provide plausible values for BCAs of federal projects that are funded by income taxes, they are less appropriate for BCAs of locally funded projects, especially those funded by property taxes. In these contexts, a METB of 17 cents per dollar, which was specifically estimated for property taxes, could more plausibly be used for local projects funded by property taxes (Ballard et al. 1985).

As mentioned earlier, estimates of the METB are rarely incorporated into BCAs. There are exceptions, however. One can use these studies to illustrate the impact of its inclusion in an analysis. Greenberg, Walter, and Knight (2013) used a value of 0.2 for the METB and found that estimates of the net social benefits of Britain's Employment Retention and Advancement demonstration decrease by around 15 to 20 percent once the METB was included. Constantatos and West (1991) used a much larger METB value of 0.5 in estimating the social rates of return to elementary, high school, and university educations in Canada in 1980. Their estimates of the returns varied from 6 to 18 percent, depending on educational level and their alternative assumptions about the extent to which differences in incomes for different educational groups reflected raw ability. Their estimates were one to two percentage points lower when the METB cost was included. Heckman et al. (2010) also estimated the rate of return of the well-known Perry Preschool Program using a 0.5 estimate of the METB as their base case. For sensitivity 
tests, they also used estimates of zero (i.e., excluding the METB) and 0.8. Their estimated 7 to 10 percent rate of return falls by a percentage point or two when the METB equals 0.5 , as against not including it. Thus, at least to the extent that these size effects are representative, incorporating METB into BCA studies would have relatively modest, although not trivial, effects.

\section{Taking Distributional Goals into Account}

Distributional goals may be taken into account in a number of ways. One approach tries to incorporate distributional impacts within the allocative efficiency framework. A second approach considers distributional impacts within some explicit social welfare function (SWF) framework. In our view, neither of these approaches is optimal. After discussing both approaches, we argue that multi-goal analysis is a more informative and transparent way to consider both efficiency and distributional impacts.

\subsection{Distributional Impacts within the Allocative Efficiency Framework}

Core BCA assesses benefits in terms of the maximum amounts that individuals would be willing to pay for policy impacts they view as favorable and the minimum amounts that they would accept in compensation for policy impacts they view as unfavorable. There are at least two views on what this actually means.

Zerbe (2004) follows Adam Smith in his Moral Sentiments' persona and argues that individuals might very well be willing to pay for policy impacts that they view as making the 
distribution of wealth more equal. ${ }^{5}$ The algebraic sum of these amounts would thus be an additional benefit that should be included in BCA. ${ }^{6}$ In other words, Zerbe proposes to treat the wealth distribution as a non-use good akin to existence values that environmental economists estimate using stated preference methods. The inclusion of monetized moral sentiments as a benefit category in BCA would take account of those distributional values for which individuals would be willing to trade consumption goods. However, inclusion of this benefit category would be unlikely to take full account of the distributional values relevant to policy choice for two reasons.

First, in making policy, political representatives have roles as both trustees and delegates (Pennock 1979). As pure delegates, representatives would appropriately interpret monetized moral sentiments as capturing their constituencies' preferences for distribution. However, as trustees, representatives appropriately take account of all social values, including those values for which individuals are not willing to sacrifice consumption. For example, some individuals might not be willing to give up consumption to protect the freedom of speech of an unpopular minority, but representatives in their trustee role might well believe that freedom of speech has inherent value: not just to protect the current unpopular speaker, but also to protect the freedom of speech of others in the future. For these trustees, allocative efficiency incorporating moral sentiments would not provide a sufficient basis for policy choice.

Second, with or without the inclusion of moral sentiments, the potential Pareto improvement principle does not guarantee that any proposed policy with positive net benefits

\footnotetext{
${ }^{5}$ A number of economic historians identify two somewhat distinct Adam Smith personas: the one manifested in The Wealth of Nations and the other in a Theory of Moral Sentiments. However, Coase (1976), for one, argues that Smith was consistent in his view that the welfare of others was intrinsic to a true understanding of rational "self-interested" behavior (see also Evansky 2005). ${ }^{6}$ These amounts would almost certainly have to be estimated by stated preference methods.
} 
would produce an actual Pareto improvement, only that it would be possible to do so if combined with compensation for those bearing net costs. Even if decision-makers were to consistently apply BCA to the portfolio of public policies — which would ensure that the consumption pie keeps getting bigger - its application could not guarantee that there would be no individual who would bear a net loss. Consequently, responsible delegates, along with trustees, would also consider distributional values beyond monetized moral sentiments.

In contrast to Zerbe, Acland (2020) argues against the inclusion of monetized moral sentiments in core BCA. He does so because he believes that moral sentiments differ in an important way from consumption goods: the motivations and values that inform individual consumption choices are not relevant to the way they should be valued in BCA, but motivations and values are central to discourse over how we should value moral sentiments. The monetization and inclusion of moral sentiments in net benefits obscures their underlying motivating values, and therefore may obfuscate discourse about rights and distributional values. Acland further argues that a practical consequence of including moral sentiments may result in either over- or under-counting distributional impacts, the former if representatives ignore positive benefits attributed to preferences for distributional impacts in their own global assessments of distributions and the later if representatives assume that the monetization fully captures distributional values. In view of these potential problems with inclusion of moral sentiments in BCA, Acland argues for a modified version of the potential Pareto criterion that monetizes only impacts for which we believe consumer sovereignty should govern.

Whether or not one accepts Acland's fundamental argument for limiting BCA to impacts based on consumer sovereignty, his concern that inclusion of moral sentiments reduces its informational value deserves consideration. We agree with the perspective that BCA best 
contributes to good public policy by facilitating explicit consideration of the tradeoff between allocative efficiency and other social values, such as a more equal distribution of wealth. Indeed, as discussed in Section 3.2, we are skeptical of those SWFs that seek to take account of distributional and efficacy impacts within a single metric because they obscure the tradeoffs. In view of all the uncertainties involved in BCA, good practice usually involves communicating the components of benefits and costs, as well as net benefits. If one were to monetize moral sentiments, it would be especially important to convey this component of benefits to help avoid over- or under-counting of distributional values as Acland warns.

As we argue elsewhere, the consumer sovereignty orientation already plays an implicit, but important, role in BCA in determining how standing is determined. In practice, standing is determined based on a number of factors, including consideration of appropriate jurisdictional boundaries, legitimacy of membership within those jurisdictions, and the acceptability of preferences (Boardman et al. 2019, Chapter 2). Although the acceptability of preferences rarely receives explicit attention in $\mathrm{BCA}$, the question of acceptability played a role in the seminal articles on BCA standing (Trumbull 1990; Whittington and MacRae 1986, 1990; Zerbe 1991, 1998). For example, one practical question was whether to count the illicit earnings of criminals, (see Long et al. 1981). One could interpret the decision to reject their inclusion as an assessment that society, through its criminal laws, is not willing to treat "ill-gotten gains" as an acceptable exercise of consumer sovereignty. Providing an explicit rationale for accepting the inclusion of moral sentiments in BCA would be an appropriate task within the determination of standing.

In practice, the difficulties in monetizing moral sentiments based on stated preferences typically means that they are ignored. Even conveying the relevant attributes of the good being valued so that respondents understood what it is poses a major challenge in the design of valid 
stated preference surveys. Efforts to provide validity usually focus on estimating a willingness to pay for nonuse benefits, rather than for all benefits; this simplifies the elicitation and thereby places less cognitive burden on respondents. Conveying how policies would change the distribution of wealth (or more likely income), however, would likely be difficult. Even if a simple measure, such as the Gini coefficient, were viewed by analysts as appropriate, conveying its meaning to respondents would be difficult. The difficulty would increase substantially if multiple dimensions were relevant, such as across demographic characteristics as well as wealth groups. Further, analysts would have to be aware that the aggregate distributional effects of policies might be favored by some but opposed by others, raising the problem of combining a more accurately estimated willingness to pay with a less accurately measured willingness to accept (Weimer and Vining 2017, Carlson et al. 2016). Although some analysts have called for the development of shadow prices for specific social policy impacts with distributional implications, such as the U.S. population's willingness to pay to move a child out of poverty (Weimer and Vining 2009), these calls have gone unheeded.

In summary, including willingness to pay for the distributional impacts of policies in BCA is consistent with the principle of potential Pareto improvement. However, these benefits typically do not provide a complete assessment of distributional impacts. Further, they are rarely measured because of the challenges they pose in applying stated preference methods. As they may blur the sharp distinction between allocative efficiency and other social values, analysts who do measure them face an added presentational burden in ensuring that these estimates are transparent and do not inappropriately distort decision makers' assessments of distributional impacts. 


\subsection{Distributional Impacts within a Social Welfare Function Framework}

There are many welfare-based arguments for considering the distributional impacts of policies. The declining marginal utility of "things," whether of all things (the marginal utility of consumption), money (the marginal utility of income) or wealth (the marginal utility of wealth), is a ubiquitous and well-grounded assumption in economics (Marshall, 1890). Consistent with this assumption, most economic models addressing valuation assume that higher-income persons receive less welfare from a given increase in consumption (or income) than do lower-income persons. A second and quite distinct argument for considering distributional effects is that many individuals have (at least stated) preferences for a more equal income distribution (Hochman and Rogers 1969, Alesina and Giuliano 2011). One rationale is a general belief that income should be more equal because that would be fairer, a form of inequality aversion (Bolton and Ockenfels 2000). This might be based simply on individuals' deriving welfare from minimizing the indignity of those at the bottom of the income distribution. Another self-regarding rationale could be that some far-sighted wealthier individuals have preferences for redistribution to avoid civil unrest (ask not for whom the tumbrils would roll, they would roll for thee).

One approach to incorporating welfare-based distributional considerations is the SWF approach. ${ }^{7}$ Social welfare analysis requires an interpersonally comparable utility function, which transforms each possible outcome into an individual measure of utility, and a rule for choosing between the vectors of individual utilities that result from different policy alternatives (Adler 2016 and 2019). Many economists and philosophers have proposed different social welfare functions. Utilitarianism sums individual utilities. The leximin rule compares the welfare of the least well-off and ignores potentially large losses of welfare by others. Many analysts favor the

\footnotetext{
${ }^{7}$ See Scitovsky (1951) for an extensive discussion of social welfare functions.
} 
isoelastic function. There are many other potential SWFs. While each of these functions has some desirable properties, there is no consensus about which one is better.

Adler (2016, p.268) takes the view "that the SWF is a template for ethical/moral preferences...[a]n SWF constitutes a systematic framework for structuring ethical/moral (henceforth, "moral") preferences: a framework that a decision-maker who has adopted the standpoint of impartiality might wish to use in specifying her moral tastes." In effect, Adler argues that the decision-maker should perform the social welfare analysis: he or she should decide which vector of utilities is preferable and, therefore, which policy alternative is preferable. This approach would require the decision maker to compare vectors that contain the utilities of each individual in society with standing that may have literally thousands (or even millions) of components depending on the number of members of society. It does not seem likely that decision-makers have the capacity for making such comparisons. Nor should they have to. BCA should aid the decision-making of policy-makers. Thus, one might argue that the analyst should choose the "most appropriate" SWF and make a recommendation about which policy alternative has the highest social welfare. This is not easy. One possibility is to derive a set of weights — often called distributional weights — that can be used to weight individual's willingness to pay for costs and benefits in a BCA. ${ }^{8}$ Adler (2016) discusses this approach in detail. Both the utilitarian and isoelastic utility functions imply weights proportional to the marginal utility of consumption. However, there are practical difficulties, which are apparent from the Table in Adler's appendix. In order to derive distributional weights, the analyst needs, at a minimum, to specify a utility function, to know or estimate each individual's status quo

\footnotetext{
${ }^{8}$ Fleurbaey and Abi-Rafeh (2016) adopt an alternative approach and examine how fair allocation theory and happiness studies can be useful for the construction of SWFs.
} 
consumption and non-consumption attributes, and the change in each individual's consumption due to the policy alternative being evaluated. These are formidable requirements. Under some assumptions, the analyst also has to specify a coefficient of risk aversion and the degree of inequality aversion. Few analysts know how to calculate the distributional weights by applying these formulas, the data requirements may be substantial, the cost of performing BCA would be more expensive and the policy makers may not understand the process or be able to make sense of (interpret) the recommendations.

BCA takes the observed distribution of income as a given: willingness to pay is a function of ability to pay. Consistent with both theory and observed behavior, individuals' willingness to pay to reduce their own mortality risks increases with their income (Viscusi and Masterman 2017, Viscusi 2018): other things equal, those with higher incomes are likely to be willing to pay more for a given reduction in mortality risk than are those with lower incomes. Thus, in estimating the value of changes in mortality, core BCA would use higher values of a statistical life (VSL) for the avoided fatalities of higher income individuals than for those with lower incomes. Many people find this result unappealing. Indeed, U.S. federal regulatory agencies, for example, typically only use a single VSL for monetizing the value of avoided fatalities, ignoring income or wealth differences. However, such an approach is hard to justify. The use of distributional weights appeals to many as a superior way to remedy this problem. Indeed, Adler (2016, Table 4) derived distributional weights using utilitarian and isoelastic welfare functions. Under certain assumptions distributional weights can counter the higher VSL of wealthier individuals that arises in core BCA.

In conclusion, there are two major problems in applying this approach. First, there is no agreement on the most appropriate social welfare function or on its parameter values. Second, 
calculating distributional weights for individuals is very difficult due, in part, to the data requirements.

\subsection{Distributional Impacts within the Multi-Goal Analysis Framework}

In view of the impracticality of treating distributional issues through the Zerbe approach or the social welfare function approach, and given the mixture of rationales for incorporating distributional issues, their complexity, and the heterogeneity of contexts where distributional issues are of concern, we argue that it is best to treat the effects of distributional impacts separately from their effects on allocative efficiency. In our view, combining efficiency and distributional impacts into a single metric obfuscates the importance of each impact and is likely to confuse decision-makers. Depending on one's perspective, multi-goal analysis is either a complementary or an alternative framework (Weimer and Vining 2017). It can be expanded to take factors beyond efficiency and distribution into account, such as budgetary impact and political feasibility. Such impacts, although very important to decision-makers in the real world, are ignored in all of the approaches discussed thus far.

The multi-goal framework has many advantages:

- It does not require complicated SWF analysis or controversial weights

- It is "doable" by analysts in government, consulting companies, or academia with basic training in BCA

- It is not prohibitively expensive

- Decision-makers can understand the information and make their own judgments about how to trade-off different goals. 
Within the multi-goal framework, we suggest that distributional issues be treated in the following manner. First, unweighted net benefits should always be computed. That is, analysts should conduct core BCA that includes the METB and computes the net social benefits to society in aggregate. Then, if distributional considerations appear relevant and important, and the necessary data exist, analysts should also provide benefit and cost estimates for different income groups (Krutilla 2005). Generally, these estimates will include the net impacts on groups from all project-related impacts, whether manifesting through taxes and transfers or other induced changes in consumption. Finally, in order to provide further guidance to policymakers, a simple form of distributional weighting might be considered.

Individual distributional weights are not used in practice. Instead, analysts assign each individual to one of a few groups and apply the same weight to everyone in each group. Because distributional weights based on contingent valuation to address preferences for a more equal distribution are extremely difficult to derive for reasons discussed in Section 3.1, and weights based on SWFs that adjust for diminishing marginal utility confront major problems as discussed in Section 3.2, we suggest weighting schemes that do neither.

Gramlich (1990) proposed a weighting scheme based on his estimates of the deadweight loss associated with a representative income transfer program. He estimated that it costs around $\$ 1.50$ to $\$ 2.00$ to redistribute a dollar through such a program. (Note that these estimates imply that the deadweight loss from income transfer programs is larger than that arising from income taxes.) Using the high end of this range for illustrative purposes, Gramlich's findings imply that if the net benefits to low income persons from a program under consideration-say, a training program for low-wage workers - are a third of the net costs to the higher income persons who fund the program, then a simple welfare program can do it less expensively. Moreover, assuming 
that participants and those paying for the program are the only persons affected by the program, its net social benefits are negative. On the other hand, if the net benefits to low income persons were three-quarters of the net costs to higher income persons, the training program is superior to a welfare program as an instrument of redistribution, even though the program's net social benefits are negative. Thus, existing welfare programs provide a benchmark to which programs under consideration can be compared.

An alternative approach is to compute internal or break-even distributional weights. Under this approach, the weight for the higher income group would first be set to one and then the weight for the lower income group would be computed by dividing the estimated NPV for the former group by the NPV for the latter group. Thus, if the net benefits to low income persons from a program under consideration are a third of the net costs to higher income persons, the breakeven weight for low income persons would be three. Given this weight, the program being analyzed would just break even. If net benefits to low income persons were three-quarters of the net costs to higher income persons, the weight for low income persons would be 1.33, again the weight at which the program would just break even. As illustrated in the following paragraph, policymakers can use these breakeven weights to formulate a judgment as to whether the benefits received by low income persons should be given a higher or lower weight than that implied by the internal weight.

It should be apparent that using such weighting schemes are only relevant for programs that result in reductions in overall social efficiency but make low-income persons better off or increase social efficiency but make low-income persons worse off. In other words, there must be a trade-off between program effects on allocative efficiency and those on the income distribution. In fact, breakeven weights can only be computed under such circumstances, and this 
does not always occur. For example, Boardman et al., (2018) examined 26 BCAs of welfare-towork programs where distributional impacts are of obvious importance. They found that higher income taxpayers who effectively funded the programs and the lower income participants of the programs were both better off in nine cases and both were worse off in seven. In only 10 of the 26 programs were there tradeoffs between efficiency and desirable redistribution. Within these 10, three had a breakeven weight of greater than two and a positive unweighted social NPV, but a negative NPV for participants. If one uses Gramlich's benchmark weight of two, the implication is that these programs should be adopted even though the income distribution would be less equal. In contrast, three programs had a breakeven weight in excess of two and a negative unweighted social NPV, but a positive NPV for participants. In these cases, use of Gramlich's benchmark implies that these programs cannot be defended even though they would result in improved the income distribution. A policymaker may, of course, wish to use weights other than Gramlich's as a benchmark.

\section{A Review and Criticism of BPR's Argument for Ignoring the METB}

BPR assume that the goal of policy analysis and BCA is to maximize social welfare, which reflects both allocative efficiency and the income distribution. Rather than considering the effects of the policy on allocative efficiency and the income distribution independently, in our view BPR combine them in a unique and unjustified way. This is shown most clearly in BPR's Table 1 where they assume that the goal is "a comprehensive measure of welfare" (p. 387). The goal of this comprehensive measure of welfare is to maximize net social benefits (calculated correctly with the METB taken into account), denoted NSB, plus the benefits of income redistribution from taxation, denoted $\mathrm{F}$, plus the benefits of redistribution by the policy measure, 
The current tax system can be assumed to be broadly consistent with the current political and societal preferences. This tax system will roughly reflect the preferences and decision-making power of the successive governments and their constituents. The resulting tax system is a specific combination of distortionary taxes and distributional benefits. Financing public expenditure with less distortionary taxes would also have been possible, but apparently the distributional benefits of the actual choice of distortionary

\footnotetext{
${ }^{9}$ More generally, however, as indicated by a previous paper by the same authors (van der Pol, Bos, and Romijn, 2018), they are reluctant to use distributional weights, stating in the paper's abstract that their use "may be demanding, prone to misuse and might distract attention from the decision problem at hand. Ultimately, welfare weighting could undermine support for BCA."
} 
taxes provide sufficient compensation for the welfare loss due to these distortions. A correction for the MEB is then not necessary. BCAs can then proceed using MCPF $=1$ resulting in BCA-outcomes that are consistent with the preferences for (in) equality as laid down in the current tax(-benefit) system and with other government policy.

Given their assertion that E is "broadly counterbalanced" by F, BPR argue that E can and should be ignored in BCAs.

In making this argument, BPR move a long distance beyond the individualistic microeconomic foundations of BCA, which was briefly described in Section 2: perhaps "a bridge too far." Even if one believes it is not "too far," its foundations are weak as BPR present no empirical evidence that $\mathrm{F}$ does approximately offset $\mathrm{E} .{ }^{10}$ Indeed, we contend there is no straightforward way to determine the extent to which F actually offsets E, although it seems evident that $\mathrm{E}$ and $\mathrm{F}$ have opposite signs. BPR putatively cut the Gordian knot by maintaining that tax systems in representative systems of government embody an optimal tradeoff between income redistribution and efficiency. They do not clarify whether they believe that this only pertains to the Netherlands, the reference point in their article, or to other countries as well. We think it is clear that it is, in general, a heroic assumption for multiple reasons.

BPR maintain that they maximize a "comprehensive measure of welfare" but do not specify a SWF. Rather, they claim that "the tax system will roughly reflect the preferences and decision-making power of the successive governments and their constituents" (pp. 392-3). However, it is not evident that any existing tax system actually represents the preferences of that

\footnotetext{
${ }^{10}$ Brennan (2014) argues that one practical "advantage of BCA is that it is based on decentralized measures of benefit. The evaluation data are "out there," in principle exogenous to the policy decision process. Ideally, all of those interested in a policy outcome can obtain the same evidence on its costs and benefits, derived ultimately from demand curves on the benefit side and cost or supply curves on the cost side." However, the data are not "out there" to determine the extent to which F offsets E.
} 
country's current residents for several reasons. A specific policy may be funded out of one particular component of the system (say, federal income taxes), but a redistributive tax system incorporates numerous other components (e.g., state and local taxes; sales and value added taxes; and transfer programs). Even if the system as a whole were accurately to reflect preferences, the individual components may not. Moreover, it is difficult to even measure the effects of tax systems on the fairness of the income distribution and thus for policymakers or BCA analysts to formulate an overall reasoned judgment about a system's optimality (Guillaud, Olckers, and Zemmour 2017; Causa and Hermansen 2019, especially p. 25).

It is not clear what BPR mean by the term "the tax system." If there was a desire to offset deadweight loss by redistributing income, would that be accomplished through taxes alone as BPR appear to imply or through some combination of taxes and transfer payments? In many, if not most, countries, transfers are more important for redistribution than are taxes (Causa and Hermansen 2019). Additionally, in some countries public pensions can be an important source of redistribution. Furthermore, in accessing the effect of the tax system on the distribution of income, it is not clear whether policy makers would use the statutory tax schedules or estimated actual tax burden to estimate redistribution.

Even if $\mathrm{E}$ and $\mathrm{F}$ were equal and of opposite signs in any given country, such as the Netherlands, that is not necessarily the case in other countries. For example, both legal tax avoidance and illegal tax evasion can vary considerably by income across jurisdictions (Barrios 2017; Joumard et al. 2012). In sum, the aggregate level of redistribution across countries can be very different and, in some countries, effective rates can be very different from statutorily specified rates. 
It is a strong (and unjustified) assumption that marginal tax rates only reflect progressive distributional considerations. ${ }^{11}$ For example, Congress (or any sensible legislature) may be appropriately worried about setting tax rates too high because of a concern that high rates will create work and investment disincentives. Also, in representative governments, constituents substantially impacted by polices (so-called concentrated interests) are more likely to monitor and lobby representatives than constituents who individually are not substantially impacted (socalled diffuse interests). Consequently, the concentrated interests tend to receive more favorable policies than the diffuse interests because they have stronger incentives to monitor and lobby (Olson 1965, Wilson 1980). In the context of tax policies, the concentrated interests can lobby for special treatments that may go largely unmonitored by most voters. These advantageous treatments need not be in terms of relatively visible statutory tax rates, but can affect what is counted as income, deductions, and credits. More generally, just as there are well-recognized market failures that require corrective collective action to achieve efficient allocations of resources, there are recognized "government failures" that tend to lead to inefficiencies in the full range of collective decisions made by governments (Weimer and Vining, 2017). Further, in federal systems, tax policies are subject to the problems of government failures at both the national and subnational levels and from the interactions between the levels of government.

Finally, it is worth noting that BPR exclude M from their measure of social welfare. Thus, the BPR measure of NPV incorporates only a partial measure of effects of the policy on the income distribution.

\footnotetext{
${ }^{11}$ This is one reason that distributional weights based on political decisions, which was suggested by Eckstein (1961), have not been widely adopted.
} 


\section{Conclusion: Swim in Your Own (Efficiency) Lane}

In our view, efficiency accounting in BCA requires the inclusion of METB. The information that is required to plausibly compute the METB is available in many circumstances, although it is an arena where further research is welcome. BPR argue that the goal of BCA is to facilitate the identification of policies that increase social welfare, which requires in their view consideration of efficiency and distributional impacts. However, they do not explicitly specify the form of the SWF on which their combination is based. Rather, they argue at a general level that tax systems contribute to a socially desirable redistribution. Furthermore, and most importantly, they argue that the benefit of redistribution resulting from the taxes needed to fund a policy approximately offsets the losses associated with the METB and, consequently, the METB can be ignored. Problematically, though, there is no reason to believe that this is the case and there is no straightforward way to determine whether it is.

In effect, BPR argue for a SWF that combines efficiency and distribution in a unique, but unjustified way. This combination reflects the distributional impacts of some limited version of taxation, and so of redistribution, but it fails to consider the distributional impacts of the policy itself. Even without these limitations, we argue that, from both a decision-making and BCA perspective, it is more informative for policy choice to maintain a separation between efficiency and other social values. It is unclear whether combining them can be confidently implemented and can adequately take account of distributional concerns. If analysts or decision-makers insist on combining distributional considerations with efficiency into a single metric — and this can and probably should be done only under limited circumstances - then distributional weighting could be used for that purpose. Even then, however, pure estimates of efficiency impacts should also be provided. 


\section{References}

Abelson, Peter. 2020. “A Partial Review of Seven Official Guidelines for Cost-Benefit Analysis." Journal of Cost-Benefit Analysis, 11: 1-22

Acland, Dan. 2020. “What's In, What's Out? Towards a Rigorous Definition of the Boundaries of BCA.” Goldman School, University of California, Berkeley, Working Paper.

Adler, Mathew D. 2016. "Benefit-Cost Analysis and Distributional Weights: An Overview." Review of Environmental Economics and Policy, 10(2): 264-285.

Adler, Mathew D. 2019. Measuring Social Welfare: An Introduction. New York: Oxford University Press.

Alesina, Alberto, and Paola Giuliano. 2011. "Preferences for Redistribution." In Handbook of Social Economics, vol. 1, North-Holland, 93-131.

Arrow, Kenneth J. 1994. “Methodological Individualism and Social Knowledge.” American Economic Review, 84(2): 1-9.

Ballard, Charles L., John B. Shoven, and John Whalley 1985. "The Total Welfare Cost of the United States Tax System: A General Equilibrium Approach." National Tax Journal, 38(2): $125-40$.

Barrios, Salvador, Bent Greve, M. Azhar Hussain, Alari Paulus, Fidel Picos, and Sara Riscado. 2017. "Measuring the Fiscal and Equity Impact of Tax Evasion: Evidence from Denmark and Estonia." JRC Working Papers on Taxation and Structural Reforms No 05/2017, JRC10962. Seville: European Commission, Joint Research Centre.

Boardman, Anthony E., David H. Greenberg, Aidan R. Vining, and David L. Weimer. 2018. Cost-Benefit Analysis: Concepts and Practice. 5th ed. New York, NY: Cambridge University Press. 
Bolton, Gary E. and Axel Ockenfels. 2000. "ERC: A Theory of Equity, Reciprocity, and Competition.” The American Economic Review, 90(1): 166-193.

Bos, Frits, Thomas van der Pol, and Gerbert Romijn. 2019. "Should Benefit-Cost Analysis Include a Correction for the Marginal Excess Burden of Taxation?" Journal of BenefitCost Analysis, 10(3): 379-403.

Brennan, Timothy J. 2014. "Behavioral Economics and Policy Evaluation,” Journal of BenefitCost Analysis, 5(1): 89-109.

Causa, Orsetta and Mikkel Hermansen 2019. Income Redistribution through Taxes and Transfers Across OECD Countries. Paris: OECD Economics Department Working Paper No. 1453.

Chetty, Raj (2015). "Behavioral Economics and Public Policy: A Pragmatic Perspective." American Economic Review, 105(5): 1-33.

Carlson, Deven E., Joseph T. Ripberger, Hank C. Jenkins-Smith, Carol L. Silva, Kuhika Gupta, Robert P. Berrens, and Benjamin A. Jones. 2016. "Contingent Valuation and the Policymaking Process: An Application to Used Nuclear Fuel in the United States." Journal of Benefit-Cost Analysis, 7(3), 459-487.

Coase, Ronald. 1976. “Adam Smith's View of Man.” Journal of Law and Economics, 19(3): $529-546$.

Constantatos, C. and E.G. West. 1991. "Measuring Returns from Education: Some Neglected Factors." Canadian Public Policy, 17: 127-138.

Dahlby, Bev 2008. The Marginal Cost of Public Funds: Theory and Application. Cambridge MA: The MIT Press. 
Eckstein, Otto. 1961. “A Survey of the Theory of Public Expenditure Criteria.” In James M. Buchanan. (Ed.), Public Finance Needs, Sources and Utilization. Princeton, NJ: Princeton University Press.

Evansky, Jerry. 2005. “Adam Smith’s Theory of Moral Sentiments: On Morals and Why They Matter to a Liberal Society of Free People and Free Markets." Journal of Economic Perspectives, 19(3): 109-130.

Fleurbaey, Marc and Rossi Abi-Rafeh. 2016. "The Use of Distributional Weights in Benefit-Cost Analysis: Insights from Welfare Economics.” Review of Environmental Economics and Policy. 10(2): 286-307.

Fujiwara, Daniel 2010. The Department for Work and Pensions Social Cost-Benefit Analysis Framework: Methodologies for Estimating and Incorporating the Wider Social and Economic Impacts of Work in Cost-Benefit Analysis of Employment Programmes. U.K.: Department for Work and Pensions Working Paper No. 86.

Gramlich, Edward M. 1990. A Guide to Benefit-Cost Analysis, $2^{\text {nd }}$ ed. Englewood Cliffs, NJ: Prentice Hall.

Greenberg, David, Johanna Walter, and Genevieve Knight. 2013. "A Cost-Benefit Analysis of the Random Assignment UK Employment Retention and Advancement Demonstration.” Applied Economics, 45(31): 4535-4354.

Guillaud, Elvire, Matthew Olckers, and Michael Zemmour 2017. "Four Levers of Redistribution: The Impact of Tax and Transfer Systems on Inequality Reduction.” EconPapers, available at: https://econpapers.repec.org/paper/lisliswps/695.htm. 
Hausman, Daniel M. 2018. "Philosophy of Economics." The Stanford Encyclopedia of Philosophy (Fall 2018 Edition). Edward N. Zalta (ed.). URL = <https://plato.stanford.edu/archives/fall2018/entries/economics/>.

Heath, Joseph. 2005 (revised 2015). "Methodological Individualism.” The Stanford Encyclopedia of Philosophy (Spring 2015 Edition), Edward N. Zalta (ed.).

Heckman, James J., Seong Hyeok Moon, Rodrigo Pinto, Peter A. Savelyev, and Adam Yavitz. 2010. The Rate of Return to the HighScope Perry Preschool Program.” Journal of Public Economics, 94: 114-128.

Hicks, John R. 1939. “The Foundations of Welfare Economics.” Economic Journal, 49(196): $696-712$.

Hochman, Harold M., and James D. Rodgers. 1969. "Pareto Optimal Redistribution." American Economic Review, 59(4): 542-557.

Hodgson, Geoffrey M. 2007 “Meanings of Methodological Individualism.” Journal of Economic Methodology, 14(2): 211-226.

Joumard, I., M. Pisu, and D. Bloch. 2012. "Less Income Inequality and More Growth - Are They Compatible?" Part 3. Income Redistribution via Taxes and Transfers Across OECD Countries, Paris: OECD Economics Department Working Papers, No. 926, OECD Publishing, http://dx.doi.org/10.1787/5k9h296b1zjf-en.

Judd, Kenneth L. 1985. "Marginal Excess Burden in a Dynamic Economy," Economics Letters, 18: 213-16.

Kahneman, Daniel, Jack L. Knetsch and Richard H. Thaler. 1990. "Experimental Tests of the Endowment Effect and the Coase Theorem," Journal of Political Economy, 98(6), $1325-1348$. 
Kaldor, Nicholas. 1939. "Welfare Propositions of Economics and Interpersonal Comparisons of Utility.” Economic Journal, 49(195): 549-552.

Krutilla, Kerry. 2005. "Using the Kaldor-Hicks Tableau Format for Cost-Benefit Analysis and Policy Evaluation." Journal of Policy Analysis and Management, 24(4): 864-875.

Long, David A., Charles D. Mallar, Craig V.D. Thornton. 1981. "Evaluating the Benefits and Costs of the Job Corps.” Journal of Policy Analysis and Management, 1(1), 55-76.

Marshall, Alfred.1890. Principles of Economics. London: Macmillan.

Niskanen, William A., Jr. 1991. “A Reflection on Bureaucracy and Representative Government." In André Blaise and Stéphane Dion, eds., The Budget Maximizing Bureaucrat: Appraisals and Evidence. Pittsburgh: University of Pittsburgh Press: 13-31. Norris, Pippa. 2020. “Measuring Populism Worldwide.” Harvard Kennedy School. RWP20-002. Office of Management and Budget. 2019. Marginal Excess Tax Burden as a Potential Cost Under E.O. 13771. December 6. https://www.regulations.gov/document?D=OMB-2017$\underline{0002-0055}$.

Olson, Mancur. 1965. The Logic of Collective Action: Public Goods and the Theory of Groups. Cambridge, MA: Harvard University Press.

Pennock, J. Rolland. 1979. Democratic Political Theory (Princeton, N.J.: Princeton University Press.)

Plott, Charles R. and Kathryn Zeiler. 2005. "The Willingness to Pay-Willingness to Accept Gap, the "Endowment Effect," Subject Misconceptions, and Experimental Procedures for Eliciting Valuations.” American Economic Review, 95(3): 530-45. 
Robinson, Lisa A. and James K. Hammitt. 2011. "Behavioral Economics and the Conduct of Benefit-Cost Analysis: Towards Principles and Standards," Journal of Benefit-Cost Analysis, 2(2): 1-51.

Scitovsky, Tibor. 1941. “A Note on Welfare Propositions in Economics.” Review of Economic Studies, 9(1): 77-88.

Scitovsky, Tibor. 1951. "The State of Welfare Economics." American Economic Review, 51(3): $301-315$.

Talvitie, Antti. 2018. "Jules Dupuit and Benefit-Cost Analysis: Making Past to be the Present." Transport Policy, 70(C): 14-21.

Tran, Chung and Sebastian Wende. 2017. "On the Marginal Excess Burden of Taxation in an Overlapping Generations Model,” TTPI Working Paper 7/2017. Canberra, Australia: Research School of Economics, Australian National University.

Trumbull, William N. 1990. "Who Has Standing in Cost-Benefit Analysis?" Journal of Policy Analysis and Management, 9(2), 201-218.

Viscusi, W. Kip. (2018) Pricing Lives: Guideposts for a Safer Society. Princeton, NJ: Princeton University Press.

Viscusi, W. Kip, and Clayton J. Masterman. 2017. "Income Elasticities and Global Values of a Statistical Life.” Journal of Benefit-Cost Analysis, 8(2): 226-250.

van der Pol, Thomas Frits Bos, and Gerbert Romijn, 2018. Distributionally Weighted CostBenefit Analysis: From Theory to Practice. Netherlands: CPB Netherlands Bureau for Economic Policy Analysis Discussion Paper 364.

Weimer, David L. 2017. Behavioral Economics for Cost-Benefit Analysis: Benefit Validity When Sovereign Consumers Make Mistakes (New York: Cambridge University Press). 
Weimer, David L. and Aidan R. Vining. 2009. “An Agenda for Promoting and Improving the Use of CBA in Social Policy.” In David L. Weimer and Aidan R. Vining, eds., Investing in the Disadvantaged: Assessing the Benefits and Costs of Social Policies. (Washington, D.C. Georgetown University Press), pp. 249-271.

Weimer, David L. and Aidan R. Vining. 2017. Policy Analysis: Concepts and Practice. $6^{\text {th }}$ ed. New York, NY: Routledge.

Weintraub, E. Roy. 1983. “On the Existence of a Competitive Equilibrium: 1930-1954.” Journal of Economic Literature, 21(1): 1-39.

Whittington, Dale, and Duncan MacRae Jr. 1986. "The Issue of Standing in Cost-benefit Analysis." Journal of Policy Analysis and Management, 5(4), 665-682.

Whittington, Dale, and Duncan MacRae. 1990. "Comment: Judgments about Who Has Standing in Cost-benefit Analysis." Journal of Policy Analysis and Management, 9(4), 536-547.

Wilson, James Q. 1980. The Politics of Regulation. New York, NY: Basic Books.

Zerbe Jr, Richard O. 1991. “Comment: Does Benefit-Cost Analysis Stand Alone? Rights and Standing." Journal of Policy Analysis and Management, 10(1), 96-105.

Zerbe Jr, Richard O. 1998. "Is Cost-benefit Analysis Legal? Three Rules." Journal of Policy Analysis and Management,17(3), 419-456.

Zerbe, Richard O. 2004. "Should Moral Sentiments Be Incorporated into Benefit-Cost Analysis? An Example of Long-Term Discounting." Policy Sciences, 37(3-4): 305-318. 